several observatories, of the magnitudes of Nova Geminorum No. 2, are published in No. 4624 of the Astronomische Nachrichten. In addition to the tables giving the magnitudes recorded at the Berlin Observatory, Herr Freundlich publishes a light-curve showing the variations of the nova's magnitude from March I4 to May I8, I9I2. This curve agrees fairly well with that previously published by Herr FischerPetersen, and shows maxima, successively decreasing in intensity, on March 14, 23, April 3, 19, and May 1.

Possible Changes of a Lunar Feature.-In the January number of L'Astronomie, M. Pierre Stoïan directs the attention of lunar observers to a small "hill" which, according to his observations, undergoes changes of form and size. This small feature lies to the north of the line joining Thebit and Birt, and about half-way between the former and the small crater at the northern end of the Straight Wall. M. Stoian points out that Nasmyth recorded nothing in this position, Neison saw a double peak, and the being a wavy line, each minute being especially marked; the images of the transit-threads are also impressed upon the plate, so that any plate may be measured or re-measured at leisure, the time of starting the exposure having been recorded. The excellence of the images is shown by a plate accompanying the paper, and a comparison of Herr Trümpler's with other results promises well for the photographic recording of star transits.

\section{THE MARINE BIOLOGICAL STATION AT PORT ERIN.}

THE twenty-sixth annual report of the Liverpool I Marine Biology Committee gives evidence of the rapidly increasing importance of the laboratory at Port Erim as a centre for research and for the instruction of students. The number of workers has more than doubled during the last six years; there were sevent four workers during the year I9y2. The extensi

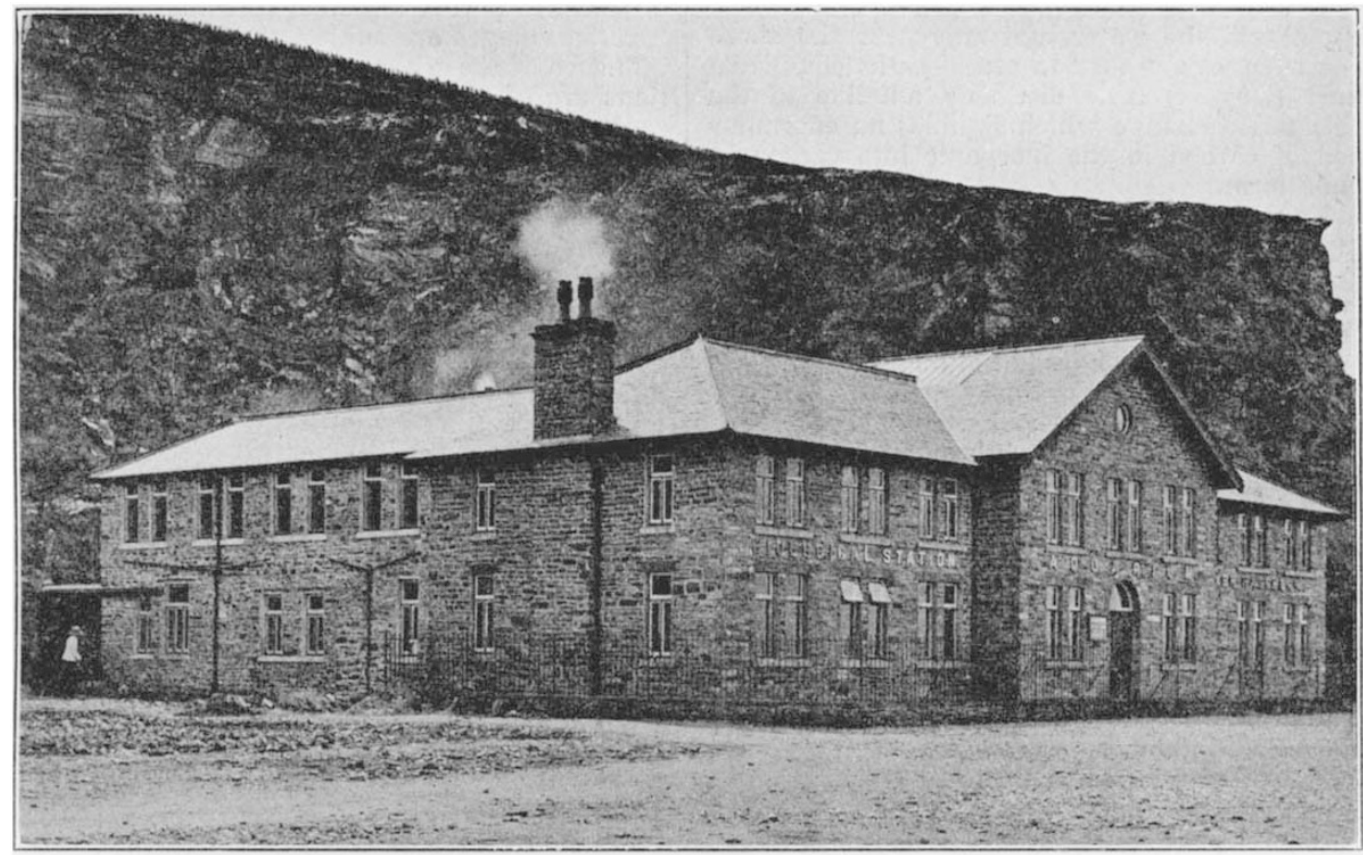

Fig. x.-The Port Erin Biological Station from the north-east.

Paris photographs show a crescent-shaped eminence which to Gaudibert was an oval; others have recorded it as larger than the smaller of the two small craters in the N.E. wall of Thebit, while to some observers it has appeared to be smaller. The feature appears to be worth further attention on the part of selenographers.

Photographic Transit Observations.-By the munificence of Messrs. Krupp, Prof. Ambronn was able to secure a photographic transit apparatus for use at the Göttingen Observatory in the early part of 19II. The instrument has been tested and used by Herr $R$. Trümpler, who describes it and the results secured in No. 4620 of the Astronomische Nachrichten. The focal length of the Göttingen instrument is $180 \mathrm{~cm}$., the aperture $18 \mathrm{~cm}$, and photographic transits of stars down to the eighth magnitude may be secured. A slight relative displacement every second results in the photographic trace of each star effected two years ago has been fully occupied, and the director (Prof. Herdman) reports that already further accommodation for research is urgently required.

Among noteworthy matters mentioned in the report are the weekly lessons and demonstrations given by the curator (Mr. H. C. Chadwick) to the boys from the local secondary school.

Prof. B. Moore and his colleagues are carrying out an extensive physiological and chemical investigation into the nutrition and metabolism of marine organisms. The results show that the amount of organic carbon present in the sea-water is almost negligible, being well below one milligramme per litre of water, and that Pütter's estimates are incorrect. They also show that, while the plankton-supply, as found generally distributed, may prove sufficient for the nutrition of such sedentary animals as sponges and ascidians, it is quite inadequate for active animals, such as crustaceans, molluscs, and fishes. These latter, however,

NO. 2258 , VOL. 90] 
are able to seek out their food, and are not dependent only upon what they may filter from the sea-water. The investigation has also brought to light a notable change in the reactions of sea-water at different seasons of the year, no doubt in correlation with the development of vast quantities of plankton-organisms.

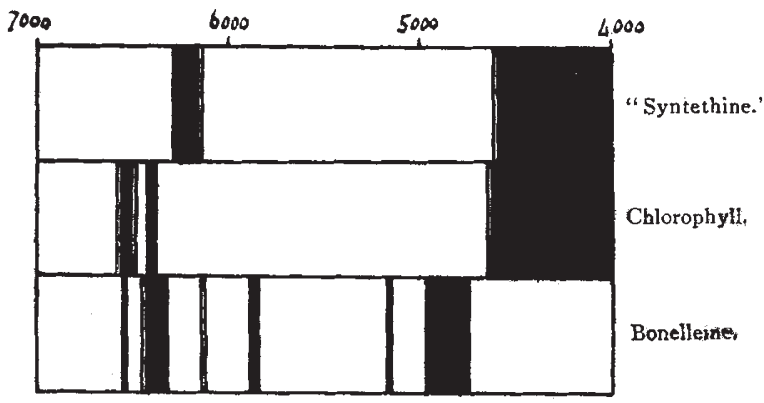

Fig. 2.-Absorption bands of pigments.

In spring (Aprii) the water, not only near the shore but in the open sea, is acid to phenolphthalein, while in summer (August) it is distinctly alkaline to the same indicator, a change which signifies an enormous conversion of carbon in the inorganic into carbon in the organic form.

Prof. Moore, Dr. Adams, and others have studied the chemical changes taking place in the reproductive organs of the sea-urchin. They have found that, under normal conditions of nutrition, the amount of food consumed by a sea-urchin is many times that required for the ordinary metabolic uses of the animal. The excess is converted into storage products-glycogen, lecithides, and fats-which, throughout the non-breeding period, accumulate in the reproductive organs in quantities as great as are usually found in the liver or hepato-pancreas of other animals, and form a reserve for use during the breeding season.

Prof. Herdman has continued his observations on the occurrence of the dinoflagellate Amphidinium on the beach at Port Erin, and records certain variations in the form of this organism, and the alternate appearance in the same area, during the early part of the year, of Amphidinium and of diatoms ( $c f$. Nature, November 28, I9I2, p. 371).

Prof. Herdman and his assistants have collected and examined, during 1912, about 400 samples of plankton from Port Erin and the neighbourhood. These show that diatoms, dinoflagellates, and copepods succeed each other in the summer plankton of the Irish Sea. The autumnal phyto-plankton increase was greater than usual in 1912, immense numbers of diatoms, chiefly Chætoceras, being present in the latter part of September. Plankton gatherings were also made along the chain of the Outer Hebrides, and proved to be oceanic in character.

During this Hebridean cruise, specimens of the ascidian Syntethys hebridicus were dredged. They were pale green when alive, but when placed in spirit became mauve or violet in colour. The colour is due to a new pigment, syntethine, the absorption-bands of which differ from those of chlorophyll and bonelleinc (see Fig. 2).

$$
\text { NO. } 2258 \text {, VOL. 90] }
$$

\section{NOTES ON THE CEREMONIES OF THE HOPI. 1}

MR. H. R. VOTH is known to all students of $\mathrm{V}$ North American ethnology for his researches into the sociology and religion of various Pueblo groups, and now, owing to the resources of the Stanley McCormick benefaction, they are indebted to him for further studies on the Hopi of Arizona. The description of the Oraibi winter and summer Marau ceremonies is the result of several partial observations in different years; as the ceremonies are sometimes going on day and night, it is a physical impossibility for one man to make an exhaustive study of a nine-day (and aight ceremony at one time, but a protracted study of the same ceremony, on different occasions, has several compensations, and it is evident that $\mathrm{Mr}$. Voth has done all that was possible to rende $e^{-}$his account accurate and as complete as circumstances would permit.

As an instance of Mr. Voth's method, it may be mentioned that he gives the names of those who take important parts in the ceremonies. Even these isolated villages are subject to the social and religious influence of the white man, so these careful investigations are of especial value. In addition, "Strife and contentions between the different factions have driven a large part of the inhabitants from the village [of

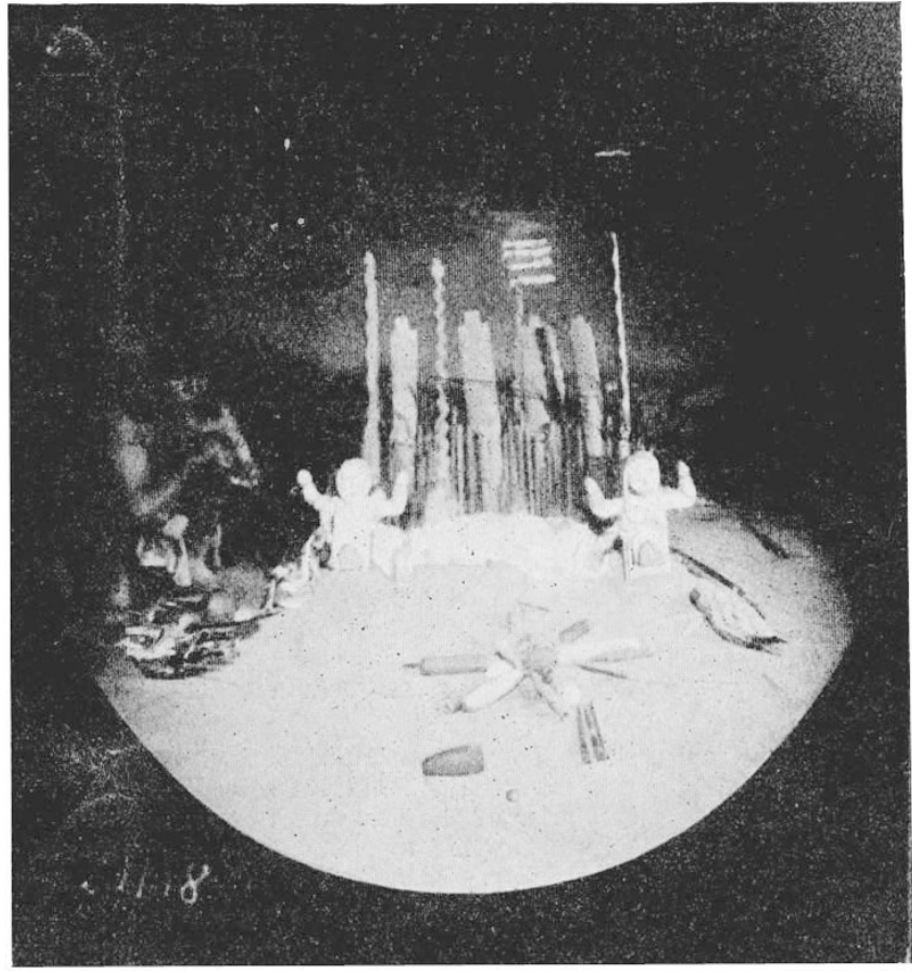

FIG. I. - The chief priest smoking over prayer offerings, From "The Oraibi Marau Ceremony."

Oraibi]. These have started new villages. This fact makes it highly probable that the Marau ceremony, as well as the others, will, in the future, never be the elaborate affairs that they used to be in the past."

1 Field Miseum of Natural History. Anthropological series, vol. xi., No, 3, Publiration No. i56. "The Oraibi Marall Ceremony." Py H. R. Voth. Pp. $88+$ plates. Vol, xi. No. 2, Publication 157. "Brief Miscel-
laneous Hopi Papers." 